\title{
FAKTOR-FAKTOR YANG MEMPENGARUHI TINGKAT ADOPSI PETERNAK TERHADAP POLA KEMITRAAN AYAM RAS PEDAGING DI KABUPATEN TABANAN
}

\author{
SUGIANTARA, I M. ${ }^{1)}$, I N. SUPARTA ${ }^{2)}$, DAN N. W. T. INGGRIATI ${ }^{2)}$ \\ 1) Program Studi Magister Ilmu Peternakan, Universitas Udayana \\ 2) Fakultas Peternakan, Universitas Udayana \\ e-mail: sugiantaramade28@gmail.com
}

\begin{abstract}
ABSTRAK
Penelitian ini bertujuan untuk mengkaji tingkat adopsi peternak pola kemitraan ayam ras pedaging dan faktor-faktor yang mempengaruhinya yaitu pengetahuan, persepsi, ketrampilan, intensitas komunikasi, sikap, dan motivasi. Penelitian dilaksanakan di Kabupaten Tabanan. Jumlah responden dari penelitian adalah sebanyak 120 responden. Pengumpulan data dilakukan dengan menggunakan metode survei menggunakan instrument penelitian berupa kuisioner. Analisis data menggunakan analisis deskriptif dan analisis jalur menggunakan metode Structural Equation Modeling (SEM). Hasil penelitian menunjukkan bahwa (1) Tingkat pengetahuan, persepsi, ketrampilan, sikap, intensitas komunikasi, dan motivasi peternak kemitraan ayam ras pedaging di Kabupaten Tabanan berada pada tingkat sangat tinggi kecuali pada tingkat persepsi dan intensitas komunikasi yang berada pada tingkat tinggi; (2) Pengetahuan, persepsi, ketrampilan, dan intensitas komunikasi berpengaruh positif nyata dengan sikap peternak kemitraan ayam pedaging di Kabupaten Tabanan; (3) Pengetahuan, persepsi, keterampilan, dan intensitas komunikasi berpengaruh positif nyata dengan motivasi peternak kemitraan ayam ras pedaging di Kabupaten Tabanan; (4) Pengetahuan, persepsi, ketrampilan, intensitas komunikasi, sikap, dan motivasi berpengaruh positif nyata dengan tingkat adopsi pola kemitraan ayam pedaging di Kabupaten Tabanan.
\end{abstract}

Kata kunci: tingkat adopsi, pola kemitraan, usaha kemitraan ayam ras pedaging

\section{FACTORS THAT INFLUENCE THE BREEDER ADOPTION LEVEL ABOUT THE PARTNERSHIP PATTERN OF BROILER CHICKEN IN TABANAN REGENCY}

\begin{abstract}
This study aims to examine the level of adoption of breeders in the broiler partnership pattern and the factors that influence it, that are knowledge, perception, skills, communication intensity, attitude, and motivation. The study was conducted at Tabanan Regency. The number of respondents was 120 respondents. Data collection was conducted by using the survey method with questionnaire research instruments. Data analysis was descriptive and path analysis by using Structural Equation Modeling (SEM) method. The results showed that (1) the level of knowledge, perceptions, skills, attitudes, communication intensity, and motivation of farmer partners in broiler breeder at Tabanan Regency was at a very high level except at the level of perception and intensity of communication that was at a high level; (2) Knowledge, perception, skills and intensity of communication have a significant positive effect on the attitude of breeder broiler partnership in Tabanan Regency; (3) Knowledge, perception, skills, and communication intensity have a significant positive effect on the motivation of the broiler breeder partnership at Tabanan Regency; (4) Knowledge, perception, skills, communication intensity, attitude, and motivation have a positive significant effect on the adoption level of broiler partnership patterns at Tabanan Regency.
\end{abstract}

Keywords: adoption rate, partnership pattern, broiler partnership business 


\section{PENDAHULUAN}

Tujuan pembangunan sektor pertanian adalah meningkatkan produksi pangan, memperluas jaringan lapangan kerja, menunjang sektor industri dan ekspor serta meningkatkan kesejahteraan dan pendapatan petani peternak. Arah pembangunan sektor pertanian khususnya sub-sektor peternakan diupayakan agar mencapai ketahanan pangan meliputi ketersediaan, stabilitas, dan keterjangkauan pangan (Dinas Pertanian dan Tanaman Pangan, 2013). Salah satu upaya untuk meningkatkan produksi pangan adalah meningkatkan populasi ayam ras pedaging, melalui usaha kemitraan yang bergerak dalam produksi ayam ras pedaging.

Suatu inovasi pada peternakan ayam ras pedaging tidak dapat berjalan dengan baik tanpa adanya arahan dari penyuluh lapangan. Peran penyuluh lapangan pada pelaksanaan penyuluhan dirasakan lebih besar memegang kendali dalam memberikan kontribusi untuk mencapai hasil yang maksimal. Hal ini terlihat dari fakta di lapangan sebagai berikut: (1) Penyuluh lapangan yang luwes dan paham permasalahan akan mampu membuat persepsi peternak terhadap penyuluh lebih berkesinambungan, sehingga saran-saran dan masukan dari penyuluhan dapat diterima dengan baik oleh peternak. (2) Keberhasilan pemeliharaan sangat berpengaruh pada pola penyuluhan yang membangun kedekatan antara penyuluh dan peternak. Selain itu, manajemen pemeliharaan dan pola pemeliharaan dapat berubah sehingga peternak mendapatkan hasil yang lebih baik dari sebelumnya. Adopsi peternak tentang pola kemitraan ayam ras pedaging menitikberatkan pada motivasi dan tujuan yang kuat untuk berhasil. Tujuan penulisan ini adalah untuk mengetahui pengetahuan, persepsi, keterampilan, intensitas komunikasi, sikap, dan motivasi peternak kemitraan ayam ras pedaging di Kabupaten Tabanan.

Tujuan penulisan ini adalah: untuk mengetahui pengaruh pengetahuan, persepsi, keterampilan, dan intensitas komunikasi terhadap sikap peternak kemitraan ayam ras pedaging di Kabupaten Tabanan; mengetahui pengaruh pengetahuan, persepsi, keterampilan, dan intensitas komunikasi terhadap motivasi peternak kemitraan ayam ras pedaging di Kabupaten Tabanan; dan mengetahui pengaruh pengetahuan, persepsi, keterampilan, intensitas komunikasi, sikap, dan motivasi terhadap tingkat adopsi pola kemitraan ayam ras pedaging di Kabupaten Tabanan.

\section{MATERI DAN METODE}

\section{Lokasi dan Waktu Penelitian}

Penelitian ini dilaksanakan di Kabupaten Tabanan pada peternak plasma kemitraan ayam ras pedaging yaitu bulan Mei tahun 2017 sampai bulan Juli tahun 2017. Lokasi penelitian ditentukan dengan metode purposif yaitu penentuan daerah yang didasarkan pada pertimbangan tertentu (Singarimbun dan Effendi, 2006). Dasar pertimbangan yang digunakan untuk memilih lokasi penelitian adalah karena populasi ternak ayam ras pedaging di Kabupaten Tabanan terbanyak dari seluruh kabupaten/kota di Provinsi Bali, sehingga diperkirakan cukup banyak masyarakat yang melakukan usaha peternakan ayam ras pedaging.

\section{Populasi Dan Sampel Penelitian}

Populasi dalam penelitian ini adalah seluruh peternak ayam ras pedaging yang melakukan kemitraan dengan perusahaan inti di Kabupaten Tabanan. Penentuan sampel sebagai responden dalam penelitian ini dilakukan secara acak dengan teknik kuota sampling (kuota random sampling). Perusahaan inti akan dikelompokkan menjadi dua bagian yaitu inti besar dan kecil. Oleh karena itu, dipilih tiga perusahaan inti besar masing-masing 20 peternak dan tiga perusahaan inti kecil masing-masing sebanyak 20 peternak, sehingga total responden adalah 120 orang. Dalam penelitian ini peternak yang dipilih adalah peternak yang sudah minimal 1 tahun menjadi mitra. Peternak yang dipilih sebagai objek penelitian tersebar merata di Kabupaten Tabanan yang dibagi menjadi 3 strata dengan pemilikan (1) $>2000$ - 4000 ekor per periode chick in, (2) $>4000$ - 6000 ekor per periode chick in, (3) >6000 ekor per periode chick in.

\section{Desain Penelitian}

Penelitian ini merupakan penelitan yang dirancang sebagai explanatory research design yaitu menjelaskan dan menganalisis hubungan antara variabel-variabel penelitian yang akan didesain menggunakan teknis analisis Partial Least Square (PLS). Variabel penelitian yang diamati adalah keberhasilan usaha peternakan pada kemitraan ayam ras pedaging, pengambilan keputusan, pengetahuan, sikap, motivasi, persepsi serta interaksi sosial.

\section{Jenis, Sumber dan Pengumpulan Data}

Data yang diperlukan dalam penelitian ini adalah data primer dan sekunder. Data primer meliputi: (1) Tingkat pengetahuan, persepsi, keterampilan, intensitas komunikasi, motivasi, dan sikap sebagai variabel bebas, (2) Tingkat adopsi peternak terhadap pola kemitraan ayam ras pedaging sebagai variabel terikat. Data sekunder diperlukan sebagai data pendukung seperti gambaran umum lokasi penelitian, populasi kemitraan, catatan performa atau hasil pemeliharaan peternak. 


\section{Pengukuran Variabel}

Variabel pengetahuan (X1), persepsi (X2), keterampilan ( $\mathrm{X}_{3}$ ), intensitas komunikasi (X4), sikap (X5), motivasi (X6), dan tingkat adopsi peternak tentang pola kemitraan ayam ras pedaging (Y1) ditabulasi dan diukur seluruh indikator dari variabel (X1), (X2), (X3), (X4), (X5), (X6), dan (Y1) menggunakan skala jenjang 5 (1,2,3,4, dan 5). Kemudian diklasifikasikan menjadi lima kategori yaitu sangat tinggi, tinggi, sedang, rendah, dan sangat rendah, Untuk pernyataan positif, respon selalu dan sangat baik diberi skor 5 , sedangkan respon tidak pernah dan buruk diberi skor 1. Demikian juga sebaliknya, untuk pernyataan negatif, respon tidak pernah dan buruk diberi skor 5, sedangkan respon selalu dan sangat baik diberi skor 1 (Singarimbun dan Effendi, 1989). Perolehan total skor untuk (X1), (X2), (X3), (X4), (X5), (X6), dan (Y1) disajikan dalam bentuk persen (\%) yang didasarkan atas skor maksimum ideal (Singarimbun dan Effendi, 1989).

\section{Analisis Data}

Analisis data dalam penelitian ini menggunakan statistika deskriptif dan statistika inferensia. Statistika deskriptif sebagai metode yang berkaitan dengan pengumpulan, penyajian dan peringkasan suatu gugus data sehingga memberikan informasi yang berguna. Statistika deskriptif disajikan dalam bentuk frekuensi, distribusi frekuensi, persentase dan rataan skor. Statistik inferensia digunakan untuk menjelaskan besar hubungan antara variabel bebas dengan variabel terikat dan digunakana untuk menguji kebenaran hipotesis dari suatu penelitian untuk mencapai tujuan penelitian (Hajarisman, 2007).

\section{HASIL DAN PEMBAHASAN}

\section{Evaluasi Deskriptif}

Dari hasil penelitian diperoleh pencapaian skor rata-rata untuk pengetahuan petani-peternak tentang pola kemitraan ayam ras pedaging adalah sebesar 4,27 yang berarti sangat tinggi. Selanjutnya 53,33\% petanipeternak memiliki pengetahuan yang sangat tinggi dan 45,00\% petani peternak memiliki pengetahuan yang tinggi tentang hal-hal yang berkaitan dengan pola kemitraan ayam ras pedaging. Persepsi yang diamati dalam penelitian ini adalah persepsi tentang pola kemitraan usaha, meliputi: kualitas sapronak, manajemen pemeliharaan dan analisis usaha kemitraan. Pencapaian skor rata-rata untuk persepsi petani-peternak adalah sebesar 4,09 yang berarti tinggi. Selanjutnya $71,67 \%$ petanipeternak memiliki persepsi yang baik tentang hal-hal yang berkaitan dengan pola kemitraan ayam ras pedaging.

Pencapaian skor rata-rata untuk keterampilan pe- tani-peternak adalah sebesar 4,38, yang berarti sangat baik. Selanjutnya $85,00 \%$ petani-peternak memiliki keterampilan sangat tinggi, disebabkan oleh pengetahuan peternak tentang pola kemitraan ayam ras pedaging sangat tinggi.

Pencapaian skor rata-rata untuk intensitas komunikasi petani-peternak adalah sebesar 3,56 yang berarti tinggi dan $69,17 \%$ intensitas komunikasinya langsung maupun tidak langsung dengan individu lain. Pencapaian skor rata-rata untuk sikap petani-peternak tentang pola kemitraan ayam ras pedaging adalah sebesar 4,22, yang berarti sangat tinggi. Selanjutnya $51,67 \%$ petani-peternak memiliki sikap yang sangat positif dan $46,66 \%$ petani-peternak memiliki sikap yang postif. Dari hasil penelitian diperoleh pencapaian skor rata-rata untuk motivasi petani-peternak adalah 4,31 dan termasuk kedalam kategori sangat tinggi. Sebagian besar $(85,84)$ petani-peternak merasa termotivasi oleh kebutuhan dan harapannya dalam mengadopsi pola kemitraan ayam ras pedaging. Pencapaian skor rata-rata untuk tingkat adopsi inovasi peternak adalah sebesar 4,34, yang berarti sangat tinggi dan sebagian besar peternak $(88,33 \%)$ memiliki tingkat adopsi inovasi yang sangat tinggi.

Tabel 1. Evaluasi deskriptif

\begin{tabular}{lccccc}
\hline \multicolumn{1}{c}{ Variabel } & \multirow{2}{*}{ Skor } & \multirow{2}{*}{ Kategori } & \multicolumn{3}{c}{ Jumlah Persentase Rata-rata } \\
& & & (orang) & (\%) & skor \\
\hline Pengetahuan & $>4,2-5,0$ & Sangat Tinggi & 64 & 53,33 & 4,27 \\
Persepsi & $>3,4-4,2$ & Baik & 86 & 71,67 & 4,09 \\
Keterampilan & $>4,2-5,0$ & Sangat Tinggi & 102 & 85,00 & 4,38 \\
Intensitas & $>3,4-4,2$ & Tinggi & 83 & 69,17 & 3,56 \\
Komunikasi & & & & & \\
Sikap & $>4,2-5,0$ & Sangat Baik & 62 & 51,67 & 4,22 \\
Motivasi & $>4,2-5,0$ & Sangat Kuat & 103 & 85,84 & 4,31 \\
Adopsi Inovasi & $>4,2-5,0$ & Sangat Tinggi & 106 & 88,33 & 4,34 \\
\hline
\end{tabular}

\section{Evaluasi Model Pengukuran}

Model pengukuran dievaluasi dengan melihat validitas konvergen, diskriminan dan reliabilitas gabungan masing-masing indikator dan variabel. Hasil evaluasi validitas konvergen, semua indikator dikatakan valid karena memiliki nilai bobot pengukuran diatas 0,50 dengan nilai t-hitung diatas 1,96 (Tabel 2).

Nilai AVE variabel penelitian di atas 0,50 . Hal ini berarti seluruh variabilitas yang terjadi pada indikatorindikator penelitian mampu dijelaskan lebih dari 50\% oleh variabilitas variabel laten daripada variabilitas yang ditimbulkan kesalahan pengukuran (Tabel 3).

Nilai akar dari average variance extracted (VAVE) variabel laten lebih besar dari koefisien korelasi variabel laten lainnya. Hal ini mengindikasikan ketujuh variable laten tersebut memiliki validitas diskriminan yang baik.

Hasil evaluasi composite reliability dan cronbach's 
Tabel 2. Evaluasi model pengukuran (outer model)

\begin{tabular}{|c|c|c|c|}
\hline Variabel & Indikator/item & Bobot & t-hitung \\
\hline \multirow[t]{4}{*}{$\begin{array}{l}\text { Pengetahuan } \\
\text { (X1) }\end{array}$} & $\begin{array}{l}\text { Pengetahuan Tentang Perjanjian Kerja } \\
\text { Sama dan Kesepakatan Kontrak Kerjasama }\end{array}$ & 0,588 & 3,168 \\
\hline & $\begin{array}{l}\text { Pengetahuan Tentang Penyuluhan/ } \\
\text { Pendampingan Pemeliharaan }\end{array}$ & 0,751 & 3,046 \\
\hline & Pengetahuan Tentang Panca Usaha Ternak & 0,589 & 2,127 \\
\hline & $\begin{array}{l}\text { Pengetahuan Tentang Penangkapan Ayam/ } \\
\text { Panen }\end{array}$ & 0,525 & 2,237 \\
\hline Sikap (X6) & Sikap Tentang Perjanjian Kerja Sama & 0,857 & 2,531 \\
\hline \multirow[t]{3}{*}{ Motivasi (X5) } & Kebutuhan & 0,554 & 2,620 \\
\hline & Harapan & 0,504 & 2,707 \\
\hline & Dorongan & 0,804 & 4,223 \\
\hline $\begin{array}{l}\text { Intensitas } \\
\text { Komunikasi } \\
\text { (X4) }\end{array}$ & Intensitas Komunikasi & 0,980 & 4,998 \\
\hline \multirow[t]{4}{*}{$\begin{array}{l}\text { Keterampilan } \\
\text { (X3) }\end{array}$} & $\begin{array}{l}\text { Keterampilan Tentang Perjanjian } \\
\text { Kerjasama }\end{array}$ & 0,620 & 3,782 \\
\hline & $\begin{array}{l}\text { Keterampilan Tentang Pengiriman } \\
\text { Sapronak }\end{array}$ & 0,722 & 4,483 \\
\hline & Keterampilan Dalam Panca Usaha Ternak & 0,820 & 4,828 \\
\hline & $\begin{array}{l}\text { Keterampilan Tentang Penangkapan Ayam/ } \\
\text { Panen }\end{array}$ & 0,625 & 3,856 \\
\hline \multirow[t]{4}{*}{$\begin{array}{l}\text { Adopsi } \\
\text { Inovasi (Y1) }\end{array}$} & $\begin{array}{l}\text { Perjanjian Kerja Sama dan Kesepakan } \\
\text { Kontrak Kerjasama }\end{array}$ & 0,578 & 2,529 \\
\hline & Panca Usaha Ternak & & \\
\hline & & 0,653 & 2,965 \\
\hline & Penangkapan Ayam/Panen & 0,570 & 2,334 \\
\hline Sikap (X6) & Sikap Tentang Perjanjian Kerja Sama & 0,857 & 2,531 \\
\hline Motivasi (X5) & Kebutuhan & 0,554 & 2,620 \\
\hline
\end{tabular}

Tabel 3. Perbandingan VAVE dengan koefisien korelasi antar variabel

\begin{tabular}{cccccccccc}
\hline Variabel & AVE & VAVE & X1 & X2 & X3 & X4 & X5 & X6 & Y1 \\
\hline X1 & 0,651 & 0,874 & 1 & & & & & & \\
X2 & 0,715 & 0,542 & 0,727 & 1 & & & & & \\
X3 & 0,692 & 0,631 & 0,536 & 0,550 & 1 & & & & \\
X4 & 0,980 & 0,854 & 0,793 & 0,692 & 0,526 & 1 & & & \\
X5 & 0,503 & 0,777 & 0,436 & 0,465 & 0,558 & 0,511 & 1 & & \\
X6 & 0,571 & 0,784 & 0,727 & 0,788 & 0,520 & 0,788 & 0,504 & 1 & \\
Y1 & 0,560 & 0,512 & 0,767 & 0,621 & 0,370 & 0,742 & 0,341 & 0,768 & 1 \\
\hline
\end{tabular}

Tabel 4. Nilai composite reliability dan cronbach's alfa variabel laten

\begin{tabular}{|l|c|c|}
\hline \multicolumn{1}{|c|}{ Variabel laten } & Composite Reliability & Cronbach's Alpha \\
\hline Pengetahuan (X1) & 0,617 & 0,610 \\
\hline Persepsi (X2) & 0,731 & 0,789 \\
\hline Keterampilan (X3) & 0,792 & 0,650 \\
\hline Intensitas Komunikasi (X4) & 0,980 & 0,854 \\
\hline Motivasi (X5) & 0,659 & 0,610 \\
\hline Sikap (X6) & 0,691 & 0,700 \\
\hline Adopsi Inovasi (Y) & 0,700 & 0,613 \\
\hline
\end{tabular}

alpha yang terdapat pada Tabel 4 tersebut, diperoleh bahwa ketujuh variabel laten yang digunakan dalam penelitian ini telah berada diatas 0,60. Sehingga dapat dinyatakan bahwa blok indikator reliabel atau andal mengukur variabel-variabel penelitian.

\section{Evaluasi Model Struktural}

Model struktural dievaluasi dengan memperhatikan $\mathrm{Q}^{2}$ predictive relevance model yang mengukur seberapa baik nilai observasi dihasilkan oleh model. $\mathrm{Q}^{2}$ memiliki nilai dengan rentang $\mathrm{O}<\mathrm{Q}^{2}<1$, semakin mendekati nilai 1 berarti model struktural dari suatu penelitian semakin baik. Sebelumnya, dalam model struktural ini terdapat dua variabel endogenus (dependen) yaitu pengambilan keputusan $\left(\mathrm{Y}_{1}\right)$ dan keberhasilan usaha $\left(\mathrm{Y}_{2}\right)$. Untuk mengetahui lebih lengkap mengenai hasil evaluasi kesesuaian model (goodness of fit model) dapat dilihat di Tabel 5 di bawah ini.

Tabel 5. Hasil evaluasi kesesuaian model

\begin{tabular}{lcc}
\hline \multicolumn{1}{c}{ Variabel laten } & $\mathbf{R}^{\mathbf{2}}$ & $\mathbf{Q}^{\mathbf{2}}$ \\
\hline Motivasi & 0,736 & \\
Sikap & 0,622 & 0,930 \\
Adopsi Inovasi & 0,867 & \\
\hline
\end{tabular}

\section{Pengujian Hipotesis}

Pengujian hipotesis dilakukan dengan resampling bootstraping untuk melihat nilai t-hitung dan besaran nilai koefisien jalur pada masing-masing jalur pengaruh langsung secara parsial. Hasil uji validasi koefisien jalur pada setiap jalur untuk pengaruh langsung dapat dilihat pada Tabel 6 di bawah ini.

Tabel 6. Hasil evaluasi validasi koefisien jalur secara parsial (uji-T)

\begin{tabular}{ccccc}
\hline Variabel & $\begin{array}{c}\text { Original } \\
\text { Sample (O) }\end{array}$ & $\begin{array}{c}\text { Sample Mean } \\
\text { (M) }\end{array}$ & $\begin{array}{c}\text { Standard } \\
\text { Deviation } \\
\text { (STDEV) }\end{array}$ & $\begin{array}{c}\text { T Statistics } \\
(\mid \text { O/STERR |) }\end{array}$ \\
\hline X1 -> Y1 & 0,468 & 0,430 & 0,191 & $2,458^{\text {sn }}$ \\
X2 -> Y1 & 0,073 & 0,095 & 0,191 & $2,383^{\text {sn }}$ \\
X3 -> Y1 & 0,164 & 0,156 & 0,122 & $2,340^{\mathrm{sn}}$ \\
X4 -> Y1 & 0,063 & 0,067 & 0,120 & $2,530^{\mathrm{sn}}$ \\
X1 -> X5 & 0,165 & 0,171 & 0,119 & $1,980^{\mathrm{sn}}$ \\
X2 -> X5 & 0,041 & 0,059 & 0,137 & $2,303^{\mathrm{sn}}$ \\
X3 -> X5 & 0,321 & 0,299 & 0,125 & $2,578^{\mathrm{sn}}$ \\
X4 -> X5 & 0,182 & 0,165 & 0,097 & 1,974 sn \\
X1 -> X6 & 0,266 & 0,238 & 0,190 & $1,995^{\mathrm{sn}}$ \\
X2 -> X6 & 0,110 & 0,107 & 0,198 & $2,556^{\mathrm{sn}}$ \\
X3 -> X6 & 0,242 & 0,189 & 0,151 & $1,988^{\mathrm{sn}}$ \\
X4 -> X6 & 0,183 & 0,151 & 0,115 & 1,997 sn \\
X5 -> X6 & 0,053 & 0,053 & 0,114 & 2,461 sn \\
X5 -> Y1 & 0,120 & 0,118 & 0,104 & 1,962 sn \\
X6 -> Y1 & 0,049 & 0,040 & 0,196 & $2,252^{\text {sn }}$ \\
\hline
\end{tabular}

Variabel yang berpengaruh nyata terhadap adopsi inovasi adalah pengetahuan, persepsi, keterampilan, intensitas komukasi, motivasi dan sikap petani-peternak ayam ras pedaging. Dalam pengujian hipotesis variabel yang berpengaruh sangat nyata $(\mathrm{P}<\mathrm{O}, \mathrm{O1})$ dapat dikatakan berpengaruh sesuai pernyataan hipotesis penelitian $(\mathrm{P}<0,05)$, karena sama-sama mengindikasikan berpengaruh hanya saja taraf signifikasinya yang berbeda, bahkan berpengaruh sangat nyata $(\mathrm{P}<\mathrm{O}, \mathrm{O1}) \mathrm{me}-$ 
miliki tingkat signifikan yang lebih tinggi dibandingkan berpengaruh nyata $(\mathrm{P}<0,05)$ sehingga hipotesis penelitian dapat juga diterima jika terdapat variabel-variabel yang berpengaruh sangat nyata.

Tabel 7. Hasil evaluasi koefisien jalur secara simultan (uji-F)

\begin{tabular}{lccc}
\hline \multicolumn{1}{c}{ Variabel predictor } & $\begin{array}{c}\text { Variabel } \\
\text { kriterium }\end{array}$ & $\mathrm{R}^{2}$ & $\mathrm{~F}$ \\
\hline $\begin{array}{l}\text { Pengetahuan, Keterampilan, Persepsi } \\
\text { dan Interaksi komunikasi }\end{array}$ & Sikap & 0,736 & $83,545^{\mathrm{sn}}$ \\
$\begin{array}{l}\text { Pengetahuan, Keterampilan, Persepsi } \\
\text { dan Interaksi komunikasi }\end{array}$ & Motivasi & 0,622 & $43,622^{\mathrm{sn}}$ \\
$\begin{array}{l}\text { Pengetahuan, Sikap, Motivasi, } \\
\begin{array}{l}\text { Persepsi, Interaksi komunikasi dan } \\
\text { Keterampilan }\end{array}\end{array}$ & Adopsi Inovasi & 0,867 & $120,673^{\mathrm{sn}}$ \\
\hline
\end{tabular}

Hasil uji-F pada Tabel 7 menunjukkan hasil evaluasi bahwa variabel pengetahuan, persepsi, keterampilan, intensitas komukasi, moviasi, dan sikap secara bersamasama berpengaruh sangat nyata $(\mathrm{p}<0,01)$ terhadap adopsi inovasi pola kemitraan ayam ras pedaging (F-hitung $>3,180$ ) dan nilai koefisien determinasi $\left(\mathrm{R}^{2}\right)$ secara berturut-turut sebesar 0,736 dan 0,622. Maka dari itu, hasil tersebut memberikan pengertian secara bersama-sama sikap maupun motivasi ditentukan oleh pengetahuan, keterampilan, persepsi dan interaksi komunikasi sebesar 73,6\% dan 62,2\%. Semakin tinggi tingkat pengetahuan, persepsi, ketrampilan, intensitas komukasi, motivasi, dan sikap, maka semakin tinggi pula tingkat adopsi pola kemitraan ayam ras pedaging.

\section{SIMPULAN}

Tingkat pengetahuan, persepsi, keterampilan, sikap, intensitas komunikasi, dan motivasi peternak kemitraan ayam ras pedaging di Kabupaten Tabanan berada pada tingkat sangat tinggi kecuali pada tingkat persepsi dan intensitas komunikasi yang berada pada tingkat tinggi. Pengetahuan, persepsi, keterampilan, dan intensitas komunikasi berpengaruh positif nyata dengan sikap peternak kemitraan ayam ras pedaging di Kabupaten Tabanan. Pengetahuan, persepsi, keterampilan, dan intensitas komunikasi berpengaruh positif nyata dengan motivasi peternak kemitraan ayam ras pedaging di Kabupaten Tabanan. Faktor yang paling berpengaruh terhadap adopsi pola kemitraan ayam ras pedaging di Kabupaten Tabanan adalah Intensitas komunikasi. Faktor-faktor berpengaruh berikutnya adalah persepsi, keterampilan, pengetahuan, sikap, dan motivasi.

\section{UCAPAN TERIMA KASIH}

Pada kesempatan ini penulis mengucapkan terima kasih peternak plasma dan perusahaan kemitraan yang telah meluangkan waktunya untuk diwawancarai, sehingga penelitian dan penulisan artikel ilmiah ini dapat terlaksana.

\section{DAFTAR PUSTAKA}

Singarimbun dan Effendi. 1989. Metode Penelitian Sosial $\mathrm{LP}_{3}$ S. Jakarta: Penelitian Sosial LP3S.

Hajarisman, N. 2007. Statistika: Badan Perkuliahan Pascasarjana. Bandung: Universitas Padjajaran.

Hasibuan, M.S.P. 2006. Manajemen Dasar, Pengertian dan Masalah Edisi Revisi. Jakarta: Bumi Aksara.

Inggriati, NWT. 2014. An Effective Extension System To Improve The Behavior of Bali Cattle Breeder in Bali. https://scolar.google.co.id. Diakses pada tanggal 8 Oktober 2018.

Suparta, N. 1992. Tingkat Adopsi Petani Dalam Proses Difusi Teknologi Hijauan Makanan Ternak Sistem Tiga Strata (HMT) Bali. Bogor: Tesis Program Pascasarjana IPB. Suparta. 2005. Pendekatan Holistik Membangun Agribisnis. Denpasar: CV. Bali Media Adhikarsa. 